\title{
The Transformation of a Unilateral Locomotor Command into a Symmetrical Bilateral Activation in the Brainstem
}

\author{
Frédéric Brocard, ${ }^{2}$ Dimitri Ryczko, ${ }^{2}$ Karine Fénelon, ${ }^{2}$ Raja Hatem, ${ }^{2}$ Delphine Gonzales, ${ }^{2}$ François Auclair, ${ }^{2}$ \\ and Réjean Dubuc ${ }^{1,2}$ \\ ${ }^{1}$ Département de Kinanthropologie Université du Québec à Montréal, Montréal, Québec H3C 3P8, Canada, and 2Groupe de Recherche sur le Système \\ Nerveux Central, Département de Physiologie, Université de Montréal, Montréal, Québec H3C 3J7, Canada
}

\begin{abstract}
A unilateral activation of the mesencephalic locomotor region (MLR) produces symmetrical bilateral locomotion in all vertebrate species tested to date. How this occurs remains unresolved. This study examined the possibility that the symmetry occurred at the level of the inputs from the MLR to reticulospinal (RS) cells. In lamprey semi-intact preparations, we recorded intracellular responses of pairs of large, homologous RS cells on both sides to stimulation of the MLR on one side. The synaptic responses on both sides were very similar in shape, amplitude, and threshold intensity. Increasing MLR stimulation intensity produced a symmetrical increase in the magnitude of the responses on both sides. $\mathrm{Ca}^{2+}$ imaging confirmed the bilateral activation of smaller-sized RS cells as well. In a high-divalent cation solution, the synaptic responses of homologous RS cells persisted and exhibited a constant latency during high-frequency stimulation. Moreover, during gradual replacement of normal Ringer's solution with a $\mathrm{Ca}^{2+}$-free solution, the magnitude of responses showed a gradual reduction with a similar time course in the homologous RS cells. These results support the idea that the MLR projects monosynaptically to RS cells on both sides with symmetrical inputs. During locomotion of the semi-intact preparation, the discharge pattern was also very similar in homologous bilateral RS cells. Anatomical experiments confirmed the presence of MLR neurons projecting ipsilaterally to the reticular formation intermingled with neurons projecting contralaterally. We conclude that the bilaterally symmetrical MLR inputs to RS cells are likely contributors to generating symmetrical locomotor activity.
\end{abstract}

\section{Introduction}

The mesencephalic locomotor region (MLR) is well conserved throughout vertebrate phyla (Grillner et al., 1998; Dubuc, 2009; Dubuc et al., 2008). It produces muscle synergies underlying different forms of locomotion such as swimming in cyclostomes and fishes, flying in birds, and stepping in tetrapods, including mammals. Despite the diverse forms of locomotion generated by the MLR, one striking feature of this brainstem region is its ability to initiate perfectly symmetrical locomotor movements on both sides in response to stimulation on one side only. Although the MLR was identified some 40 years ago (Shik et al., 1966), the

Received July 16, 2009; revised Nov. 12, 2009; accepted Nov. 12, 2009.

This work was supported by Canadian Institutes of Health Research (CIHR) Grants 15129 (R.D.), and 15176 the Fonds pour la Formation des Chercheurs et l'Aide à la Recherche (FCAR; Québec), Natural Sciences and Engineering Research Council of Canada (NSERC) Grant 217435 (R.D.), and the Fonds de la Recherche en Santé du Québec (FRSQ) [Groupe de Recherche sur le Système Nerveux (entral (GRSNC) Grant 5249]. F.B. received a fellowship from CIHR (Institute of Musculoskeletal Health and Arthritis) and GRSNC (Jasper Fellowship). D.R. received a fellowship from GRSNC. K.F. received a studentship from FRSQ. We are grateful to Danielle Veilleux for her technical assistance, to Frédéric Bernard for the graphics, and to Laurent Juvin for his comments on this manuscript. We thank Jean-François Gariépy for his help with the kinematic analyses.

Correspondence should be addressed to Dr. Réjean Dubuc, Université du Québec à Montréal, Département de Kinanthropologie, CP 8888, Succursale Centre-Ville, Montréal, Québec H3C 3P8, Canada. E-mail: rejean.dubuc@ gmail.com.

F. Brocard's present address: Laboratoire Plasticité et Physio-Pathologie de la Motricité, Centre National de la Recherche Scientifique, Unité Mixte de Recherche 6196, Université de la Méditerranée, 31 chemin Joseph Aiguier, F-13402 Marseille, Cedex 20, France.

DOI:10.1523/JNEUROSCI.3433-09.2010

Copyright $\odot 2010$ the authors $\quad$ 0270-6474/10/300523-11\$15.00/0 neural mechanisms underlying its symmetrical output remain unknown.

The MLR is known to initiate locomotion by activating reticulospinal (RS) cells that in turn project to the spinal cord locomotor networks (for review, see Grillner et al., 1998; Jordan, 1998; Orlovsky et al., 1999). Whether the symmetry results from a balanced activation of RS cells on both sides or occurs by other mechanisms downstream to RS cells is still an open question. Previous studies in decerebrate cats have shown that RS cells received inputs from the MLR on both sides (Orlovsky, 1970; Garcia-Rill and Skinner, 1987), but it was not possible to determine whether identical inputs were provided to the RS cells. Because different stimulating electrodes were used on each side, small differences in the position or the impedance of the electrodes could have resulted in the recruitment of different MLR neurons leading to different synaptic responses on both sides. Therefore, possible symmetry of inputs could not be assessed.

The lamprey brainstem is uniquely organized with pairs of identifiable RS cells on the basis of their position, size, and shape (Rovainen, 1967, 1978; Rovainen et al., 1973; Bussières, 1994). Their large size (up to $150 \mu \mathrm{m}$ ) combined with their easy access for microelectrode impalement under visual guidance make the brainstem of lampreys an excellent model for examining possible bilateral symmetry pattern in the MLR command. Taking advantage of this, we describe for the first time, with dual intracellular recordings of bilaterally homologous RS cells, symmetrical MLR inputs to RS cells on both sides. During locomotion in a semiintact preparation, there was also a bilaterally symmetrical re- 
cruitment of RS cells on both sides. Using $\mathrm{Ca}^{2+}$ imaging, we confirmed that this was also true for smaller-sized RS cells that are less accessible for dual intracellular recordings. Unilateral injections of anatomical tracers in the reticular formation revealed the presence of retrogradely labeled MLR neurons on both sides.

Parts of this work have been presented previously in abstract form (Brocard et al., 2005) and mentioned in part in a review article (Dubuc et al., 2008).

\section{Materials and Methods}

The experiments were all performed on sea lampreys (Petromyzon marinus) collected from streams entering Lake Champlain in southern Québec (Canada) or purchased from ACME Lamprey. Whereas the electrophysiological and $\mathrm{Ca}^{2+}$-imaging experiments were all performed on larval animals (9-14 cm in total body length), anatomical experiments were performed on both larval and newly transformed adult lampreys. All surgical and experimental procedures conformed to guidelines of the Canadian Council on Animal Care and were approved by the Animal Care and Use Committees at the Université de Montréal and the Université du Québec à Montréal. Special care was taken to limit any possible suffering to a minimum and to limit the number of animals used in the experiments.

Electrophysiological experiments. Electrophysiological experiments were performed in a total of 52 larval lampreys. All animals were first anesthetized with tricaine methanesulphonate (MS 222, $100 \mathrm{mg} / \mathrm{L}$; Sigma) and transferred for dissection in cold oxygenated Ringer's solution $\left(8-10^{\circ} \mathrm{C}\right)$ with the following composition (in $\mathrm{mm}$ ): $130 \mathrm{NaCl}, 2.1$ $\mathrm{KCl}, 2.6 \mathrm{CaCl}_{2}, 1.8 \mathrm{MgCl}_{2}, 4 \mathrm{HEPES}, 4$ dextrose, and $1 \mathrm{NaHCO}_{3}, \mathrm{pH}$ 7.4. A semi-intact preparation was used in 11 cases; the cranium was completely dissected free of surrounding tissues and cut open dorsally to expose the brain and rostral spinal cord, whereas the rest of the body and tail were left intact to swim freely (Fig. 1). The prosencephalon was removed after a complete transverse section. The preparation obtained was placed dorsal side up in a recording chamber continually perfused with Ringer's solution at a rate of $\sim 4 \mathrm{ml} / \mathrm{min}$. In 18 cases, an isolated brainstem preparation was obtained in the same manner except that the intact portion comprising the body and tail was completely removed after a complete transverse section. The spinal cord was cut between the first and second spinal segments.

Using sharp glass microelectrodes filled with $4 \mathrm{M}$ potassium acetate (80-130 M $\Omega$ ), paired intracellular recordings were made from homologous RS neurons in the middle (MRRN) and the posterior (PRRN) rhombencephalic reticular nucleus (Fig. 1). The signals were amplified by an Axoclamp 2A amplifier (sampling rate of $2-10 \mathrm{kHz}$; Molecular Devices). Only RS neurons with a stable membrane potential lower than $-70 \mathrm{mV}$ for $>15$ min were included in the study.

Unilateral stimulation of the MLR (Fig. 1) was performed with a glasscoated tungsten microelectrode ( $4-5 \mathrm{M} \Omega$ with a $10 \mu \mathrm{m}$ tip exposure). Single stimulus shocks ( $1.5 \mathrm{~ms}$ duration) of different intensities were delivered every $30 \mathrm{~s}$ to examine the synaptic inputs from the MLR to RS cells. In semi-intact preparations, swimming was induced by repeated electrical stimulation of the MLR (1.5-2 ms square shocks, $0.5-15 \mu \mathrm{A}$, at a frequency of 2-5 Hz) (Sirota et al., 2000; Brocard and Dubuc, 2003). Each stimulation bout lasted $\sim 20 \mathrm{~s}$, and the interval between successive trials was at least $3 \mathrm{~min}$. Alternatively, chemical stimulation of the MLR was performed by local positive pressure injection of AMPA (1 mM; Sigma) through glass micropipettes using a Picospritzer (General Valve Corporation). This was done to establish that the RS responses resulted from the activation of cell bodies in the MLR.

The data were acquired through a Digidata $1322 \mathrm{~A}$ interface with Clampex 9.0 software (Molecular Devices). Intracellular signals were analyzed with Clampfit 9.0 software. The peak amplitude of the evoked postsynaptic potentials was measured as the largest voltage deflection from the resting membrane potential. The latency was measured from the stimulus artifact to the onset of the synaptic response.

Analysis of locomotion in the semi-intact preparation. In six semi-intact preparations, electromyographic (EMG) recordings were used to monitor the presence of swimming movements. Pairs of Teflon-coated stain- less steel wires (50 $\mu \mathrm{m}$ diameter; California Fine Wire Company) were inserted into the myotomes between segments 20 and 25 (Fig. 1). The EMG signals were amplified $(10,000 \times$ ), filtered (bandwidth, $30 \mathrm{~Hz}-1$ $\mathrm{kHz}$ ) and acquired at a sampling rate of $5 \mathrm{kHz}$. The EMGs were recorded on one side only not to impede locomotor movements in the small animals. In five other experiments, we used a kinematic analysis to examine locomotor symmetry rather than EMG recordings. A video camera (30 frames/s) was positioned at the distance of $1 \mathrm{~m}$ from the recording chamber (Fig. 1) $(n=5)$. Using homemade software analysis, equally spaced points along the midline of the body of the animal were made and tracked frame by frame to permit a kinematic analysis of MLRinduced locomotion. Bilateral symmetry was assessed by comparing the left and right maximal bending angles at a specific point along the body ( $\approx 50 \%$ body length). The maximum bending angle $\left(\alpha_{\max }\right)$ between the longitudinal axis of the nonmoving part of the body and the straight line drawn between two marked points on the middle of the body (see Fig. 7B3) was compared on the left and right side for several locomotor cycles.

Data are presented in the text and in Table 1 as mean \pm SEM. A Student's $t$ test was used for statistical analysis when two groups were compared. Groups of data having a $p$ value $<0.05$ were considered significantly different.

$\mathrm{Ca}^{2+}$-imaging experiments. $\mathrm{Ca}^{2+}$-imaging experiments were performed in five larval lampreys in which the brainstem had been isolated in vitro as described above. Crystals of the calcium green dextran amine conjugate [10,000 molecular weight (MW); Invitrogen] were applied over the cut end of the spinal cord (between the first and the second spinal segments) to label RS cells retrogradely. The preparations were perfused with cold Ringer's solution overnight in the dark to allow dye transport (10-24 h). Labeled RS cells were imaged on a Nikon epifluorescent microscope equipped with a $20 \times(0.75$ numerical aperture $)$ objective. A fluorescein isothiocyanate excitation/emission filter set was used to visualize the neurons labeled with calcium green dextrans. The emitted light was captured with an intensified CCD video camera (Photometrics CoolSNAP HQ; Roper Scientific) at a rate of one to two images per second. The MLR stimulation parameters consisted of single shocks ( 1.5 ms square shocks, $0.5-15 \mu \mathrm{A})$. Using single-shock MLR stimulation, action potentials were rarely induced in MRRN RS cells and never in PRRN RS cells (Brocard and Dubuc, 2003).

Imaging data were analyzed using Metafluor imaging software (Molecular Devices). Recording sites were identified and delineated for measurement on the monitor using a mouse. Attention was focused on fluorescence changes in the cell bodies. $\mathrm{Ca}^{2+}$ responses were expressed as relative changes in fluorescence $\Delta F / F$ (percentage), whereas the changes in $\mathrm{Ca}^{2+}$ dynamics were assessed by the time course of the signals. To quantify and compare $\mathrm{Ca}^{2+}$ responses between cells, the time series were imported in a spreadsheet, and the corresponding peaks, expressed as $\Delta F / F$ (percentage), and areas $(\Delta F / F \cdot s)$ were calculated.

Anatomical experiments. Single-labeling experiments were performed in 10 newly transformed lampreys injected unilaterally in the MRRN with either Alexa Fluor 594-dextran amines (10,000 MW; $n=7$; Invitrogen) or biocytin ( $n=3$; Sigma). Double-labeling experiments were performed in vitro in four larval and four newly transformed animals. Injections of Alexa Fluor 594-dextran amines were made in the MRRN on side and Alexa Fluor 488-dextran amines (10,000 MW; Invitrogen) on the other side. The injections proceeded as follows. The MRRN cells were disrupted with a glass micropipette both superficially and deep in the medial tegmentum in which many of their dendrites are located. The goal was to damage potential descending MLR axons so that they could pick up the injected tracer. The tracers were dissolved in distilled water, recrystallized on the tip of insect pins and precisely deposited into the injection site, and kept there for at least $10 \mathrm{~min}$. In cases of bilateral injections, the second injection was made at least $4 \mathrm{~h}$ after the first one, increasing the chance for axons lesioned by the first injection to have closed. Using a second micropipette, suction was applied to remove any spill of the second tracer to prevent any contamination of the first injection site. The fact that double-labeled neurons were rarely seen in our material validates the method of double injections used here. The second tracer was then thoroughly 


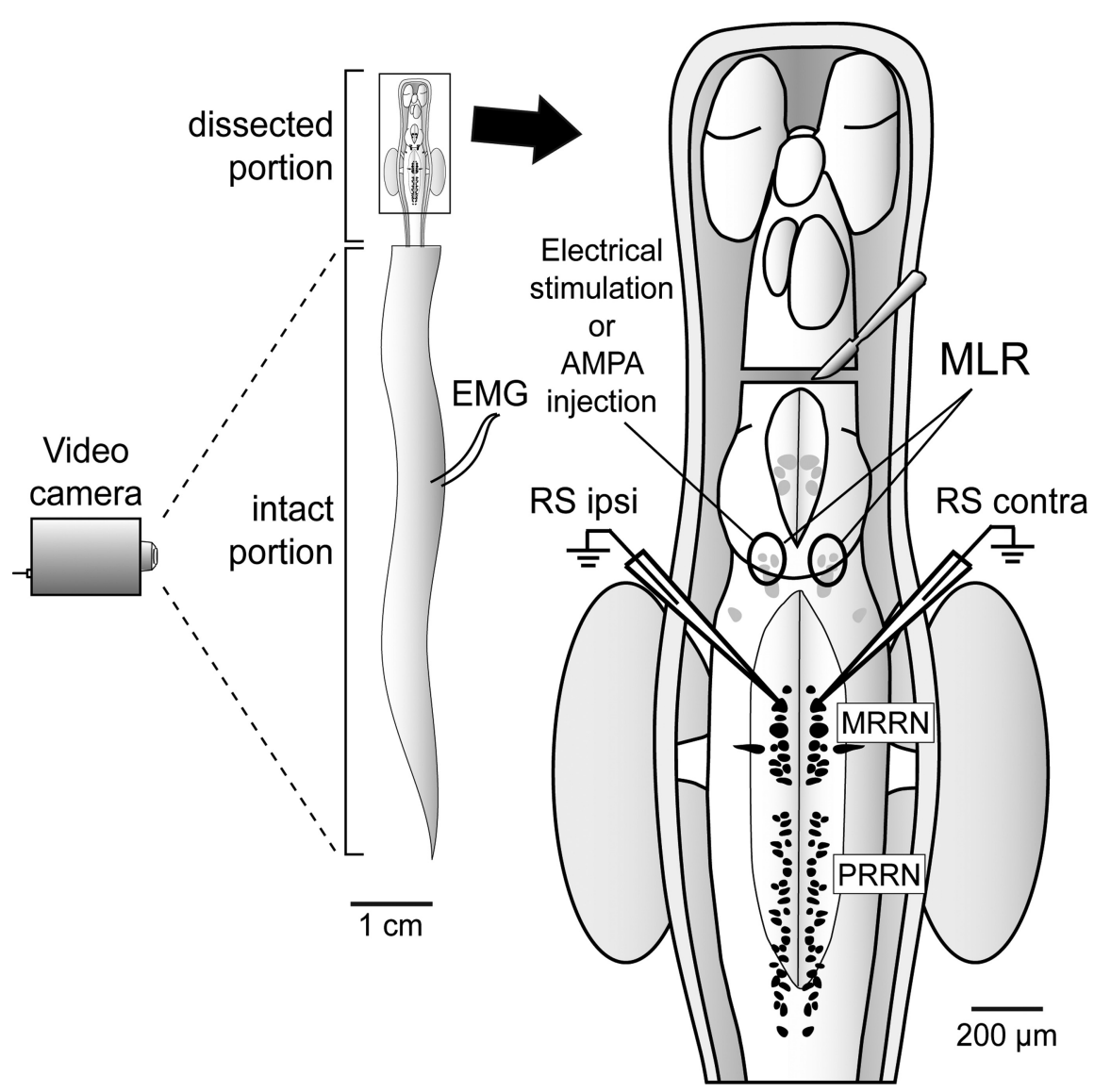

Figure 1. The experimental paradigm for the electrophysiological experiments. The left schematically represents the dorsal view of the semi-intact preparation as described in Materials and Methods. It also shows the approximate location of EMG recordings along the intact portion of the body. Movements of the animal were also recorded from above by a video camera (30 frames $/ \mathrm{s}$ ), positioned at the distance of $1 \mathrm{~m}$ from the recording chamber. The right represents an enlargement of the boxed area on the left. It shows the location of the transection of the brain just rostral to the mesencephalon, the MLR (encircled with a solid line) on both sides of the brain, and the MRRN and PRRN. Note that the brainstem preparation consisted of the brainstem plus one or two spinal segments as illustrated here. Scale bars are approximations.

rinsed away with fresh Ringer's solutions, and the preparation was transferred to a chamber continuously perfused with fresh oxygenated Ringer's solution at $7-9^{\circ} \mathrm{C}$. In addition to MRRN afferents, the medial longitudinal fasciculus and other medial longitudinal "en passant" fibers coursing deep in the tegmentum were inevitably lesioned by this injection method, including descending MLR axons directed toward PRRN RS cells.

From 18 to $42 \mathrm{~h}$ after tracer injection, the preparations were immersed in a solution of $4 \%$ paraformaldehyde and $16 \%(\mathrm{v} / \mathrm{v})$ picric acid in PBS $(0.1 \mathrm{M}, \mathrm{pH} 7.4)$ for $5-6 \mathrm{~h}$ and then transferred into a $30 \%$ sucrose solution overnight. The next day, the preparations were quickly frozen with 2-methylbutane (Fisher Scientific) at $-45^{\circ} \mathrm{C}$ and serially cut with a cryostat at $25 \mu \mathrm{m}$ thickness. The sections were collected on ColorFrost Plus microscope slides (Fisher Scientific) and allowed to dry overnight on a warming plate at $37^{\circ} \mathrm{C}$. The sections containing biocytin were then rinsed with PBS, incubated for $1 \mathrm{~h}$ in streptavidin conjugated to Alexa Fluor 594 (Invitrogen) diluted 1:200 in PBS, rinsed again with PBS, and air dried for $30 \mathrm{~min}$. All sections were coverslipped with Vectashield 4', $6^{\prime}$-diamidino2-phenylindole (DAPI) mounting medium (Vector Laboratories) and observed with an Eclipse 600 epifluorescence microscope equipped with a DXM1200 digital camera (Nikon).

All labeled neurons in the tegmentum of cross sections from the isthmic Müller cell I1 to the decussation of the lateral octavomesencephalic tract in the mesencephalon were included in the analysis. The rostrocaudal extent of the brain segment that we included in the analysis was based on previous studies showing the anatomical localization of the physiologically identified MLR (Sirota et al., 2000; Le Ray et al., 2003; Brocard et al., 2005; Ménard et al., 2007). The goal of the analysis was to identify the location and distribution of labeled neurons and provide a bilateral comparison in the number of cells. A count was made skipping one section every two, inevitably leading to underestimation of the total number of retrogradely labeled neurons but still providing a good estimation for comparing the number of cells on the ipsilateral and contralateral sides. Skipping one section out of two had the clear advantage of preventing double counting of single cells, given that the largest cells had a diameter of $<20 \mu \mathrm{m}$ and that section thickness was $25 \mu \mathrm{m}$. Low-power photomicrographs of the sections were imported in CorelDraw software (Corel), in which their contours were drawn and the location of labeled neurons indicated. These drawings were printed, taken back to the microscope, and used to positively identify and precisely locate neurons. The labeling of cell nuclei with DAPI helped in identifying the labeled neurons, and the presence of a DAPI-labeled nucleus was necessary for a neuron to be included in the analysis. Figures were designed using CorelDraw or Illustrator (Adobe Systems) software.

\section{Results}

\section{Symmetrical MLR inputs to}

\section{homologous RS cells on both sides}

RS cells on both sides (18 pairs) were recorded intracellularly in 18 in vitro isolated brainstem preparations. Of these, 12 paired recordings were performed in the MRRN (Fig. 2A) and six in the PRRN (Fig. 2B). The connectivity between the MLR and pairs of homologous RS cells on both sides was first investigated with single-shock stimulation of the MLR at different intensities. The stimulus/response relationship was established as illustrated in Figure 2, $A 1-A 3$ and $B 1-B 3$. Although the latencies of postsynaptic responses elicited in ipsilateral RS cells were significantly shorter compared with contralateral RS cells $(p<0.05$, paired $t$ test) (Table 1 ), the most stunning observation was the marked similarities in the stimulus/response relationships in homologous RS cells (Fig. 2A3,B3). In addition to the similar threshold stimulating currents for evoking depolarizing responses in homologous RS cells (Fig. 2A4,B4; Table 1) ( $p>$ 0.05 , paired $t$ test $)$, there was a symmetrical increase in the area of the bilateral responses (Fig. $2 A 1, A 2, B 1, B 2$ ). A linear regression analysis performed on the ascending part of relationships $(r>0.95)$ demonstrates similar slopes between homologous RS cells in the two reticular nuclei (Fig. 2A5,B5; Table 1) $(p>0.05$, paired $t$ test). At some point, as the stimulus current increased, the slopes did not increase further; the magnitude of synaptic responses reached a plateau that was similar in homologous $\mathrm{RS}$ cells on both sides (Fig. 2A6,B6; Table 1) ( $p>0.05$, paired $t$ test).

Because the sampling with paired intracellular recordings was limited to the large $\mathrm{RS}$ cells, $\mathrm{Ca}^{2+}$ imaging was used as a complementary approach to examine bilateral responses in smaller-sized RS cells of the MRRN (Fig. 3A1) and PRRN (Fig. 3B1). RS cells were retrogradely loaded with calcium green dextran crystals injected in the rostral spinal cord and imaged using fluorescence microscopy. As was the case for intracellular recordings of large 
MRRN

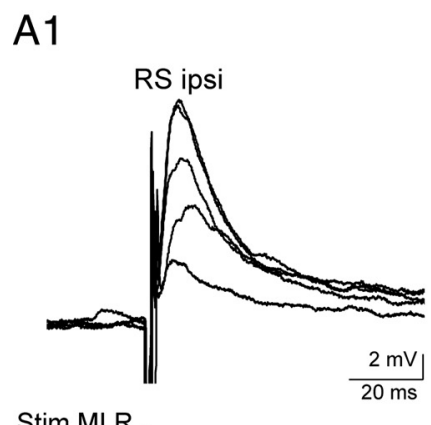

Stim MLR ,

\section{A3}

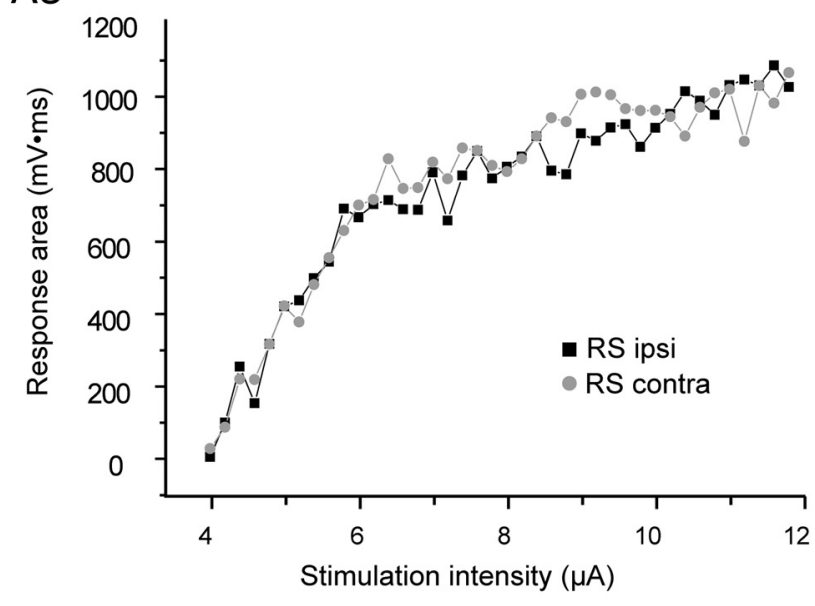

A4

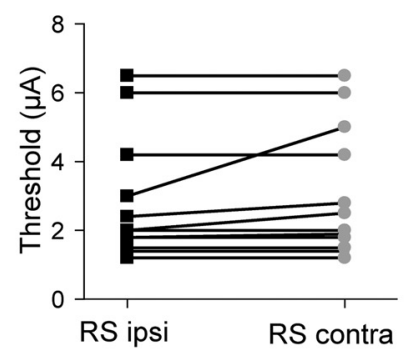

A5

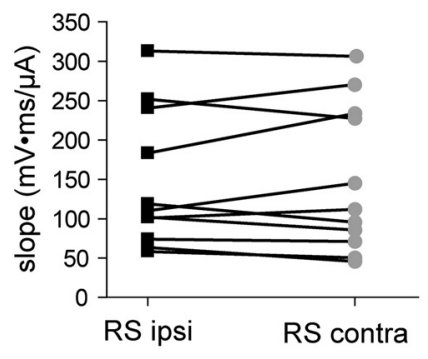

A6
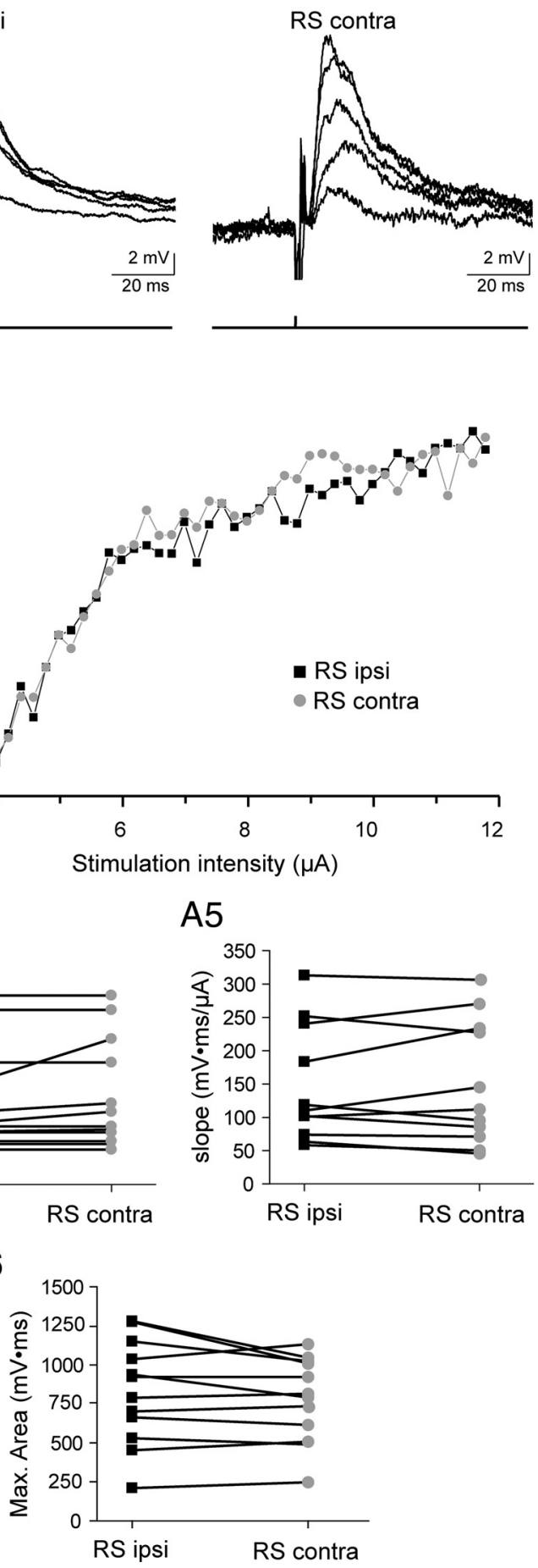

PRRN
B1

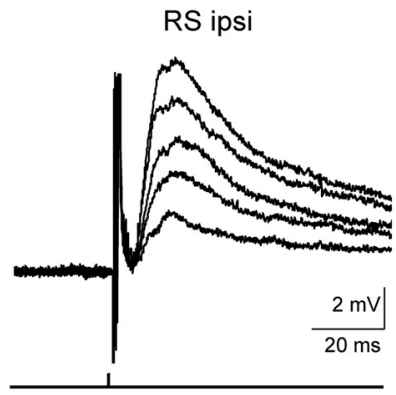

B3
B2

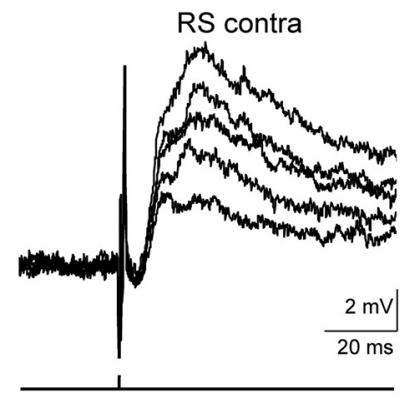

Ba

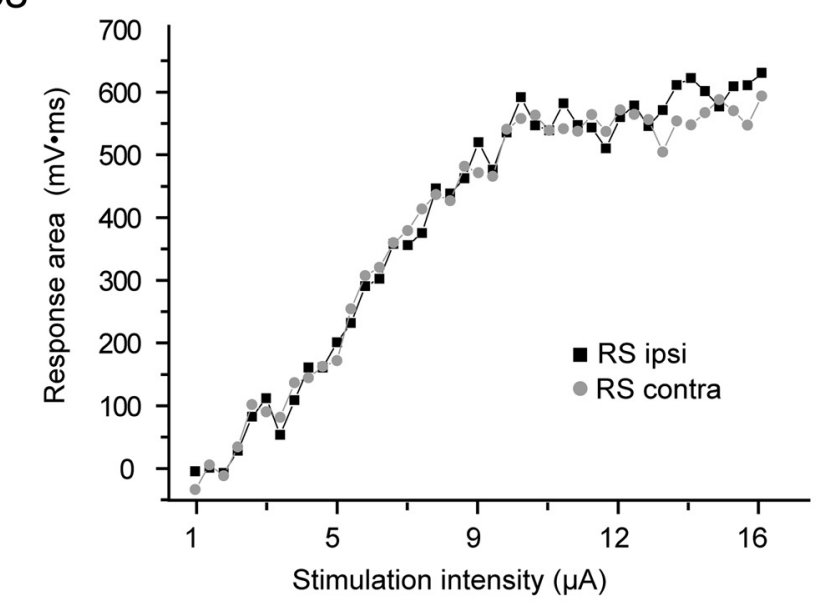

B4

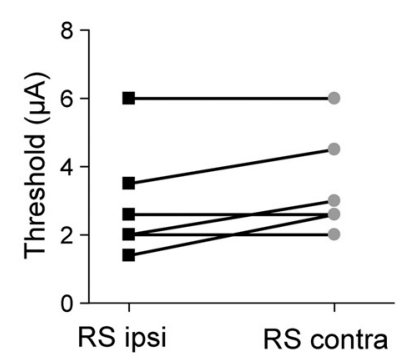

B5

B6

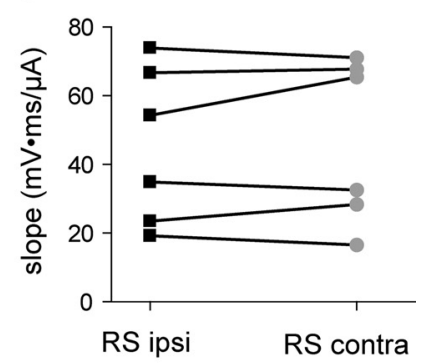

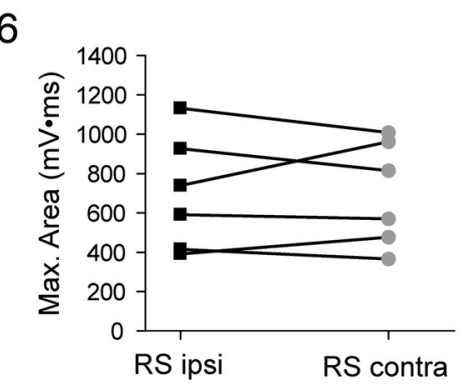

Figure 2. Synaptic responses recorded simultaneously in homologous RS cells, ipsilateral (RS ipsi) and contralateral (RS contra) to the stimulated MLR on one side. $A$, Data from MRRN cells. $\boldsymbol{B}$, Data from PRRN cells. $\boldsymbol{A 1}, \boldsymbol{A 2}, \boldsymbol{B 1}, \boldsymbol{B 2}$, Typical bilateral graded responses recorded at resting membrane potential from homologous RS cells to increasing intensity of stimulation of the $M L R$. All traces are averages of three sweeps. $A 3, B 3$, Relationship between the stimulus intensity of the MLR and the area of synaptic responses elicited in ipsilateral (black squares) and contralateral (gray circles) RS cells. $\boldsymbol{A 4}, \boldsymbol{B} 4$, Graph depicting the MLR stimulus threshold needed to induce synaptic responses in homologous RS cells. A5, B5, Graph depicting the initial slope of the stimulus/response relationship in homologous RS cells. A6, B6, Graph depicting the area of the maximal subthreshold responses in homologous RS cells. The paired intracellular recordings from RS cells in the MRRN were performed in a different preparation from those in the PRRN.

RS neurons, the smaller homologous RS neurons on both sides also displayed a symmetrical bilateral increase in relative fluorescence. This was true for smaller-sized RS cells in the MRRN ( $n=$ 8 pairs) (Fig. $3 A 2-A 4)$ and in the PRRN ( $n=6$ pairs) (Fig. $3 B 2-B 4)$. The stimulating current threshold for evoking $\mathrm{Ca}^{2+}$ responses did not differ in homologous RS cells on both sides (MRRN, $0.8 \pm 0.1$ vs $0.8 \pm 0.1 \mu \mathrm{A}, p>0.05$, paired $t$ test; PRRN, $0.92 \pm 0.04$ vs $0.90 \pm 0.04 \mu \mathrm{A}, p>0.05$, paired $t$ test). In both the MRRN and the PRRN, as the stimulating current increased, the area of the $\mathrm{Ca}^{2+}$ responses reached a maximal value, which was 
Table 1. Characteristics of postsynaptic potentials evoked in homologous RS cells of the MRRN and the PRRN after unilateral stimulation of the MLR

\begin{tabular}{|c|c|c|c|c|}
\hline & \multicolumn{2}{|c|}{$\operatorname{MRRN}(n=12)$} & \multicolumn{2}{|c|}{$\operatorname{PRRN}(n=6)$} \\
\hline & Ipsilateral & Contralateral & Ipsilateral & Contralateral \\
\hline Latency (ms) & $4.7 \pm 0.3$ & $5.8 \pm 0.4^{* * * *}$ & $7.1 \pm 0.7$ & $8.2 \pm 1.0^{*}$ \\
\hline Threshold $(\mu \mathrm{A})$ & $2.8 \pm 0.5$ & $3.1 \pm 0.5$ & $2.9 \pm 0.7$ & $3.4 \pm 0.6$ \\
\hline Maximum area (mV/ms) & $830 \pm 96$ & $779 \pm 78$ & $699 \pm 119$ & $700 \pm 109$ \\
\hline Slope $\left(\mathrm{mV} \cdot \mathrm{ms}^{-1} \cdot \mu \mathrm{A}^{-1}\right)$ & $146 \pm 26$ & $149 \pm 28$ & $45 \pm 9$ & $47 \pm 10$ \\
\hline
\end{tabular}

MRRN

A1

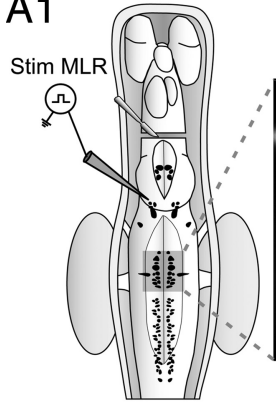

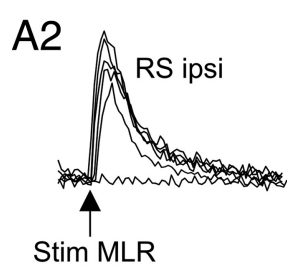
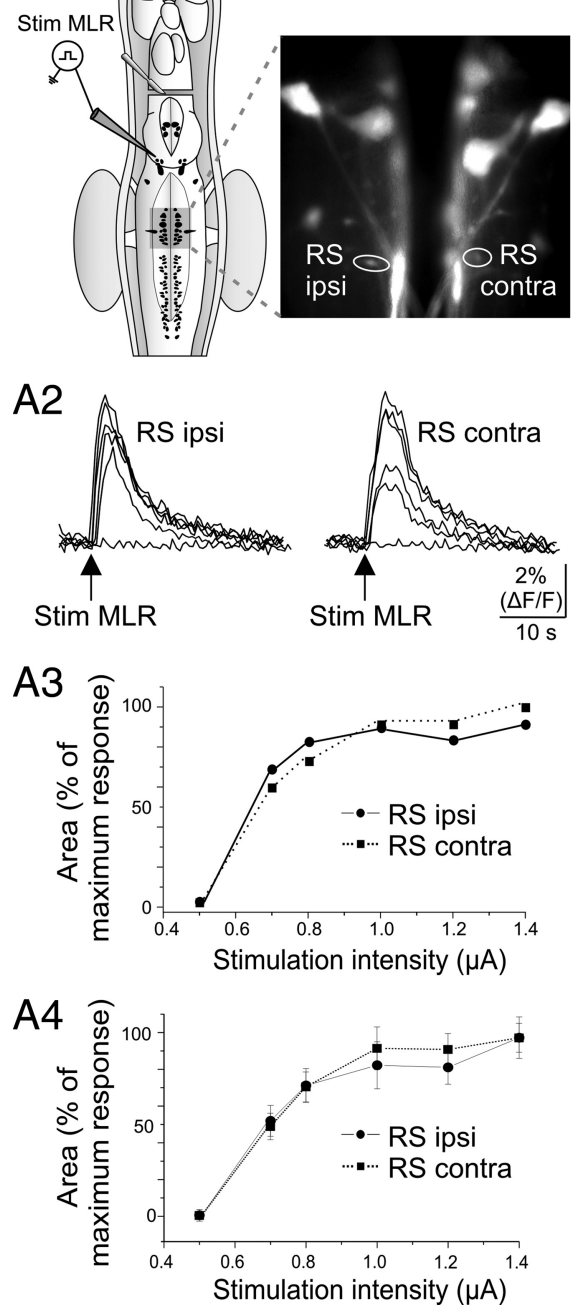

\section{PRRN}

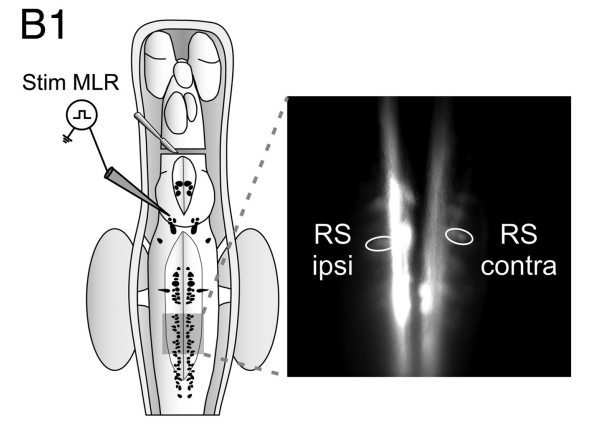

B2
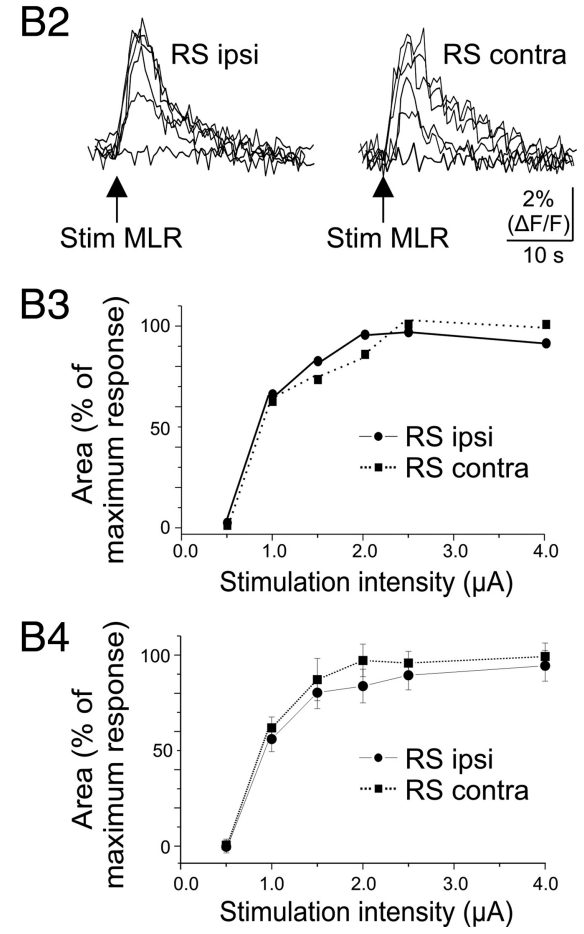

Figure 3. Symmetrical bilateral $\mathrm{Ca}^{2+}$ responses in smaller-sized RS cells after electrical stimulation of the MLR. $A, M R R N$ data. $B$, PRRN data. $A 1, B 1$, Schematic representations of the dorsal view of the brainstem of a larval lamprey with photomicrographs illustrating calcium green dextran-labeled RS cells in the MRRN (A1) and in the PRRN (B1) from the same preparation. Pairs of homologous RS cells were delineated and labeled as ipsilateral (RS ipsi) and contralateral (RS contra) to the MLR stimulation, as indicated for one example on the photomicrographs. $\mathbf{A 2}, \mathbf{B 2}, \mathrm{Ca}^{2+}$ responses in both the ipsilateral and contralateral RS cells to MLR stimulation of different intensities. Each trace was obtained at the following single-shock intensities: $0.5,0.7,0.8,1.0,1.2,1.4 \mu \mathrm{A}$ for the MRRN (A2) and 0.5, 1.0, 1.5, 2.0, 2.5, 4.0 $\mu A$ for the PRRN (B2). A3, B3, Graph illustrating the relationship between the intensity of MLR stimulation and the area of the $\mathrm{Ca}^{2+}$ responses for the pairs of $\mathrm{RS}$ cells illustrated in $\mathbf{A} \mathbf{2}$ and $\boldsymbol{B 2}$. $\boldsymbol{A 4}, \boldsymbol{B} \mathbf{4}$, Graph illustrating the relationship between the intensity of MLR stimulation and the mean \pm SEM area of the $\mathrm{Ca}^{2+}$ responses for eight pairs of RS cells in the MRRN and six pairs in the PRRN.
( $n=4$ pairs; data not shown) and were found to be highly etrical on both sides as for smaller cells and as described above using electrophysiological techniques. Together, these results strongly suggest that MLR inputs to RS cells on both Monosynaptic connectivity between the MLR and RS cells on both sides

We demonstrated previously that a large part of MLR inputs to ipsilateral RS cells is monosynaptic (Brocard and Dubuc, 2003). Because the latency of the MLRinduced synaptic responses did not depend on the stimulation current intensity (Fig. $2 A 1, A 2, B 1, B 2$ ), it was likely that the MLR inputs to contralateral RS cells was also monosynaptic. To address this, maximal subthreshold responses were recorded in the presence of high concentrations of divalent cations $\left(10.8 \mathrm{mM} \mathrm{Ca}^{2+}\right.$ / $7.2 \mathrm{mM} \mathrm{Mg}^{2+}$ ) to abolish polysynaptic while keeping monosynaptic inputs (Brocard and Dubuc, 2003). As shown in Figure $4, A 1$ and $B 1$, bilateral responses elicited in the MRRN and PRRN were reduced but still persisted. The postsynaptic potentials were reduced in area by $37.1 \pm$ 15.2 and $44.1 \pm 17.9 \%$ in ipsilateral and contralateral RS cells of the MRRN (Fig. $4 A 2)$ and by $35.3 \pm 7.2$ and $41.4 \pm 1.9 \%$ in ipsilateral and contralateral RS cells of the PRRN (Fig. 4 B2), respectively. The bilateral responses remained symmetrical when the concentrations of $\mathrm{Ca}^{2+}$ and $\mathrm{Mg}^{2+}$ were raised $(p>0.05$, paired $t$ test). Stimulation of the MLR at frequencies up to $25 \mathrm{~Hz}$ continued to elicit onefor-one, constant latency postsynaptic potentials in homologous RS cells from both the MRRN and PRRN (Fig. 4A3,B3). Additional indication of a monosynaptic connection was provided by examining the time course of synaptic transmission between the MLR and RS cells while replacing the normal Ringer's solution with a $\mathrm{Ca}^{2+}$-free solution. This approach was used previously by Brocard and Dubuc (2003). Figure 5, $A$ and $B$, compares the time course of the reduction of postsynaptic potentials from homologous RS cells from the MRRN and PRRN as the $\mathrm{Ca}^{2+}$ free solution was perfused. The synaptic responses on the two sides in both reticular nuclei showed the same gradual reduction without the appearance of failure in the graph (Fig. 5A2,B2). Together, these results suggest that there is a very significant monosynaptic projection from the MLR to RS cells on both sides. similar for neurons on both sides (MRRN, $1.0 \pm 0.3$ vs $0.9 \pm 0.2$ $\Delta F / F \cdot \mathrm{s}, p>0.05$, paired $t$ test; PRRN, $0.5 \pm 0.1$ vs $0.4 \pm 0.2$ $\Delta F / F \cdot \mathrm{s}, p>0.05$, paired $t$ test). It is noteworthy that $\mathrm{Ca}^{2+}$ responses were also examined in larger RS cells in the MRRN
Projections from the isthmic region to RS cells

The bilateral recruitment of RS cells of the MRRN from unilateral stimulation of the MLR raises questions about the underlying anatomical substrate. Experiments were designed to determine 
whether single cells on one side of the MLR projected to the MRRN on both sides or whether some cells in the MLR projected ipsilaterally whereas others projected contralaterally. First, retrograde tracer injections were made in the MRRN, and the distribution of labeled cells in the isthmic region was analyzed. A quantitative approach was used to compare six injections in three larval lampreys (two injections per animal, one on each side) and six injections in four newly transformed lampreys (two animals with two injections, one on each side, and two animals with a single injection). No statistical difference could be seen in the distribution of retrogradely labeled cells in the isthmic region between larval and newly transformed lampreys for both ipsilaterally (respectively, $51 \pm 5$ vs $52 \pm 7$ cells, $n=6 ; p>0.05, t$ test) and contralaterally (respectively, $29 \pm 6$ vs $30 \pm 4$ cells, $n=6$; $p>0.05, t$ test) projecting neurons. Conversely, there were always fewer labeled cells in the contralateral MLR $60.7 \pm$ $9.4 \%$ of ipsilateral; $n=6 ; p<0.05$ newly transformed animals; $57.6 \pm 11.2 \% ; n=$ 6; $p<0.05$ larval, paired $t$ test). We then injected the MRRN with two retrograde tracers of different colors, one on each side to examine whether some of the MLR cells bilaterally projected to the MRRN. Figure 6 illustrates the labeled cells in the MLR after such double labeling in one larval lamprey. The injection of each tracer in the MRRN yielded labeling on both sides of the MLR (Fig. 6, red dots or green dots). Double-labeled neurons were very rare, none being found in the animal illustrated in Figure 6.

\section{Homologous RS cells display similar recruitment pattern}

Experiments were performed to determine whether homologous RS cells display a symmetrical output in frequency when swimming is generated by a unilateral stimulation of the MLR. The recruitment pattern of homologous RS cells was examined during MLR-induced locomotion in 11 semi-intact preparations. Paired recordings (11 pairs) were performed from homologous MRRN cells. In most preparations, the rhythmic bursts of discharges were clearly antiphasic in the homologous RS cells on both sides (Fig. 7A1, also see inset).

Different MLR stimulation intensities were used for five pairs of RS cells recorded in five different animals. The results were quantified in details for those five pairs, and a kinematic analysis was also performed to examine the bilateral symmetry of the swimming movements. The raw traces in Figure 7A1 show a very similar discharge pattern in the ipsilateral and contralateral RS cells during repetitive electrical unilateral stimulation of the MLR at three different intensities. The increase in cell discharge frequency was identical for the ipsilateral and the contralateral RS
MRRN

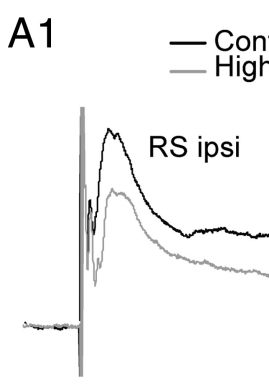

A2
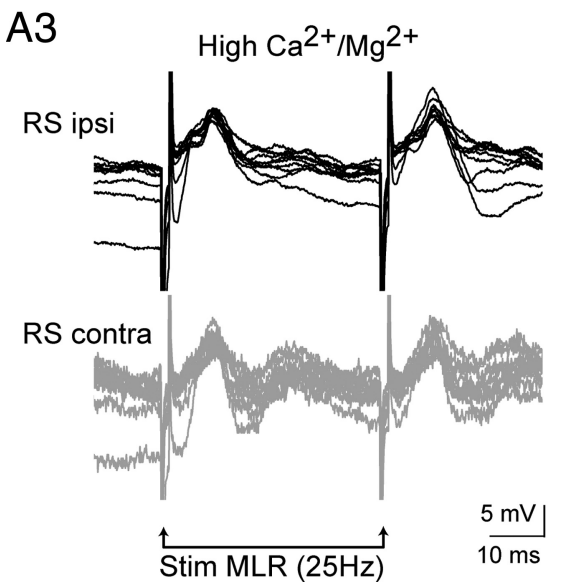

\section{PRRN}

B1
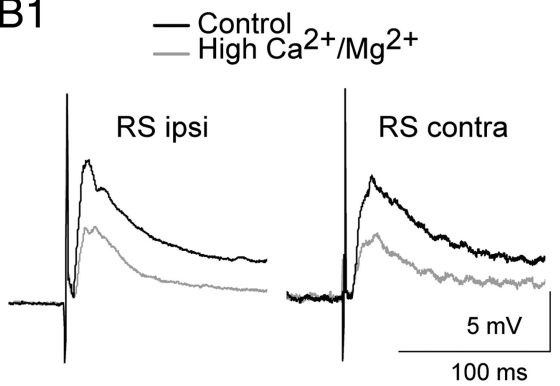

B2

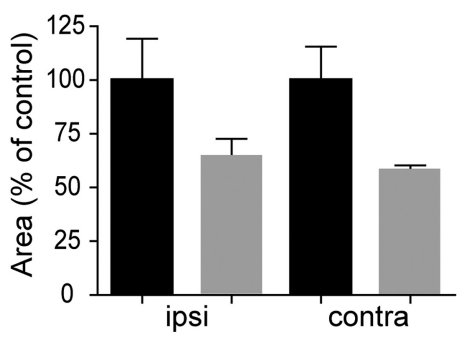

B3

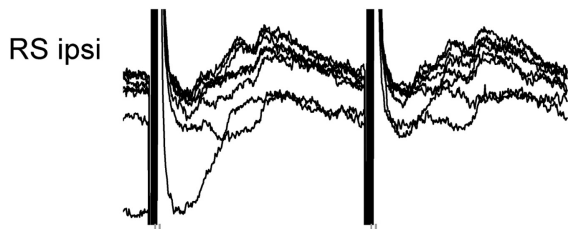

RS contra

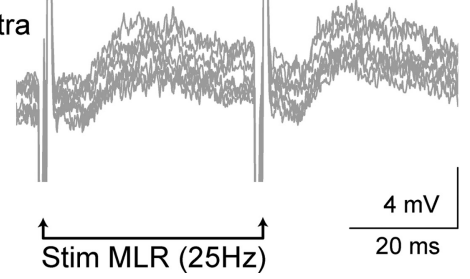

Figure 4. Effects of a high-divalent cation solution $\left(10.8 \mathrm{mM} \mathrm{Ca}^{2+} / 7.2 \mathrm{mM} \mathrm{Mg}^{2+}\right)$ on bilateral responses induced in mean peak amplitude of bilateral synaptic responses for three pairs of RS cells. The amplitude values were expressed in percentage of the control value. $\mathbf{A} \mathbf{3}, \mathbf{B}$, Bilateral responses in high-divalent cation solution during high-frequency stimulation $(25 \mathrm{~Hz})$. The recordings from the MRRN and the PRRN were performed in two different preparations.

cells (Fig. 7A2). Expressing the RS discharge as a percentage of the maximal RS frequency and the stimulation intensity as a percentage of the maximal stimulation intensity allowed us to pool the responses from five animals. The relationship between the discharge frequencies and stimulation intensities followed a cubic polynomial function for both ipsilateral $\left(R^{2}=0.78\right)$ and contralateral $\left(R^{2}=0.72\right)$ RS neurons. Interestingly, the two polynomial functions were highly similar (Fig. 7A3, solid lines). The 95\% prediction intervals were calculated for each polynomial function, and $100 \%$ (27 of 27 values) of the discharge frequencies of ipsilateral RS neurons were included in the prediction intervals of the contralateral RS neurons, whereas 96.3\% (26 of 27 values) of the discharge frequencies of contralateral RS neurons were included in the prediction intervals of ipsilateral RS neurons. Hence, ipsilateral and contralateral RS neurons showed a strongly symmetrical pattern of discharge. Similar findings were 


\section{MRRN}

A1

$\mathrm{Ca}^{2+}$ free Ringer's
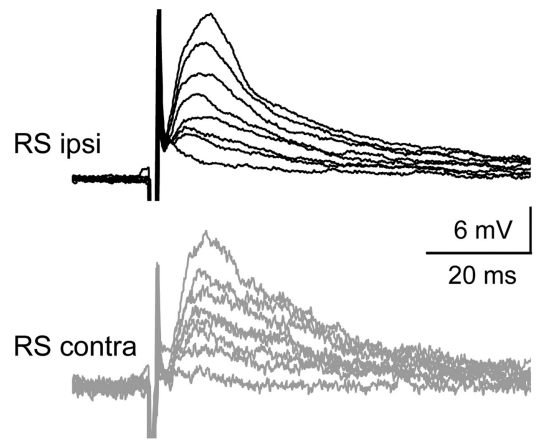

Stim MLR

A2

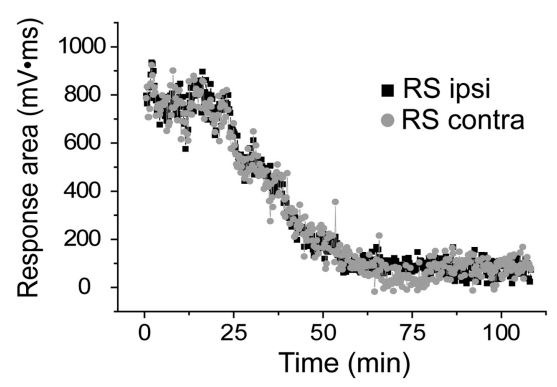

PRRN

B1

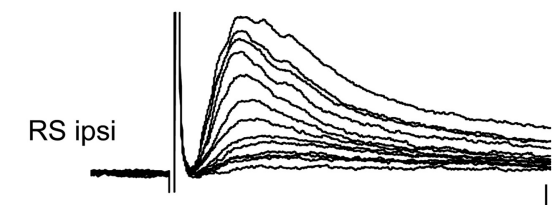

$\frac{4 \mathrm{mV}}{20 \mathrm{~ms}}$

RS contra

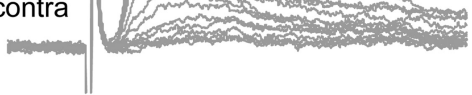

Stim MLR

B2

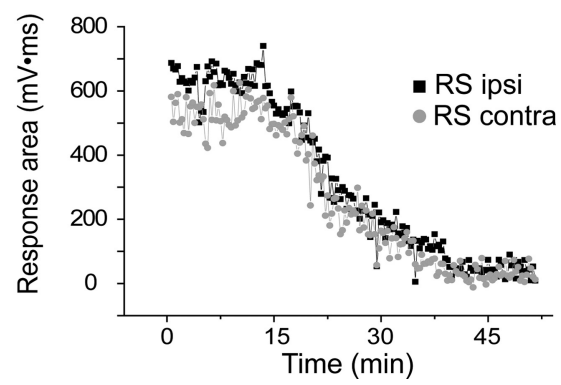

Figure 5. Effects of $\mathrm{Ca}^{2+}$-free Ringer's solution on bilateral responses induced in MRRN $(\boldsymbol{A})$ and PRRN $(\boldsymbol{B})$ RS cells by MLR stimulation. $\boldsymbol{A} 1, \boldsymbol{B} 1$, Typical gradual reduction of the synaptic responses recorded from homologous RS cells, ipsilateral (RS ipsi) and contralateral (RS contra) to the MLR stimulation, after switching to $\mathrm{Ca}^{2+}$-free Ringer's solution. $\mathbf{A 2}, \mathbf{B 2}$, Graph illustrating the response area in two homologous $\mathrm{RS}$ cells as a function of time after changing to $\mathrm{Ca}^{2+}$-free Ringer's solution. The recordings from the MRRN and the PRRN were performed in two different preparations.

observed on unilateral chemical stimulation of the MLR with AMPA in three semi-intact preparations. Homologous RS cells on both sides displayed a very similar discharge frequency (18.4 \pm 5.3 vs $17.4 \pm 2.1 \mathrm{~Hz}$ for ipsilateral and contralateral RS cells, respectively; $p>0.05$, paired $t$ test).

A unilateral stimulation of the MLR induced bouts of forward swimming. The frequency of swimming proportionally increased with the intensity of stimulation (Fig. 7B2), as described previously by us (Sirota et al., 2000). The left and right maximal bending angles of the body during the swimming bout were then calculated (see Materials and Methods) (Fig. 7B3), and they were not statistically different for the three stimulation intensities tested ( $p>0.05$, paired $t$ test) (Fig. 7B4) in the same animal. This further confirms the presence of a symmetrical swimming in response to unilateral MLR stimulation.

\section{Discussion}

The main finding of this study was the striking similarity of synaptic responses elicited in RS cells on both sides by a unilateral stimulation of the MLR. Such balanced activation of RS cells is likely to provide a very similar excitatory drive to spinal locomotor networks on both sides contributing to symmetrical locomotion. Forty years after the discovery of the MLR (Shik et al., 1966), we now provide the first direct evidence that symmetrical swimming elicited by MLR stimulation on one side results at least in part from symmetrical MLR inputs to RS cells on both sides.

\section{Synaptic inputs from the MLR to} RS cells

Previous investigation from our group showed that the MLR projects monosynaptically to RS cells located in two different reticular nuclei of the hindbrain, the MRRN and PRRN (Brocard and Dubuc, 2003). Only projections ipsilateral to the stimulation were investigated at that time. Extracellular recordings of medullary RS cell activity in cats (Iwakiri et al., 1995), newts (Bar-Gad et al., 1999), and salamanders (Kagan and Shik, 2004) showed the presence of short-latency excitations from the MLR to RS cells, likely to be monosynaptic. It is noteworthy that monosynaptic connectivity occurred for $<50 \%$ of the recorded RS cells. This contrasts with the present observations in which monosynaptic connectivity was observed for all of the RS cells tested. The difference may result from species specificity or from the greater sensitivity of intracellular recordings in which subthreshold responses can be measured, whereas using extracellular recordings only suprathreshold responses can be observed.

We now show that the MLR projects monosynaptically to RS cells not only on the ipsilateral but also on the contralateral side. This conclusion arises from the following evidence: (1) the responses evoked by the MLR exhibited an invariant latency as the stimulus intensity was increased; (2) perfusion of $\mathrm{Ca}^{2+}$-free solution showed a gradual reduction of the MLR-induced responses without failure; and (3) stimulation of the MLR in the presence of high-divalent ion concentrations still elicited synaptic responses at a fixed latency. Altogether, these observations suggest the presence of monosynaptic inputs. The longer latency of MLRinduced synaptic responses on the contralateral side could result from the expected longer pathway compared with the ipsilateral one, because the axons of MLR neurons cross to the other side. Altogether, these results indicate that there is symmetrical input from the MLR on one side to RS cells on both sides. Whether this is the case for all RS cells remains to be established. The MRRN and PRRN comprise $90 \%$ of the entire RS population in lampreys. Our electrophysiological sampling was biased toward the large RS cells, but the $\mathrm{Ca}^{2+}$-imaging results indicate that smaller $\mathrm{RS}$ cells also receive a symmetrical input from the MLR.

The symmetrical bilateral projection from the MLR to RS cells described in the present study could be a common feature in many other vertebrate species. In studies examining the connection between the MLR and hindbrain RS cells in mammals, bilateral MLR projections to the hindbrain reticular formation were found (Orlovsky, 1970; Garcia-Rill and Skinner, 1987). Using intracellular recording in decerebrate cats, Orlovsky showed that RS cells on both sides were activated by MLR stimulation (Orlovsky, 1970), but symmetrical inputs to RS cells were not observed. Indeed, responses recorded from an individual RS cell and elicited by alternate single stimulation of the ipsilateral and contralateral MLR revealed, in most cases, an asymmetry in the 

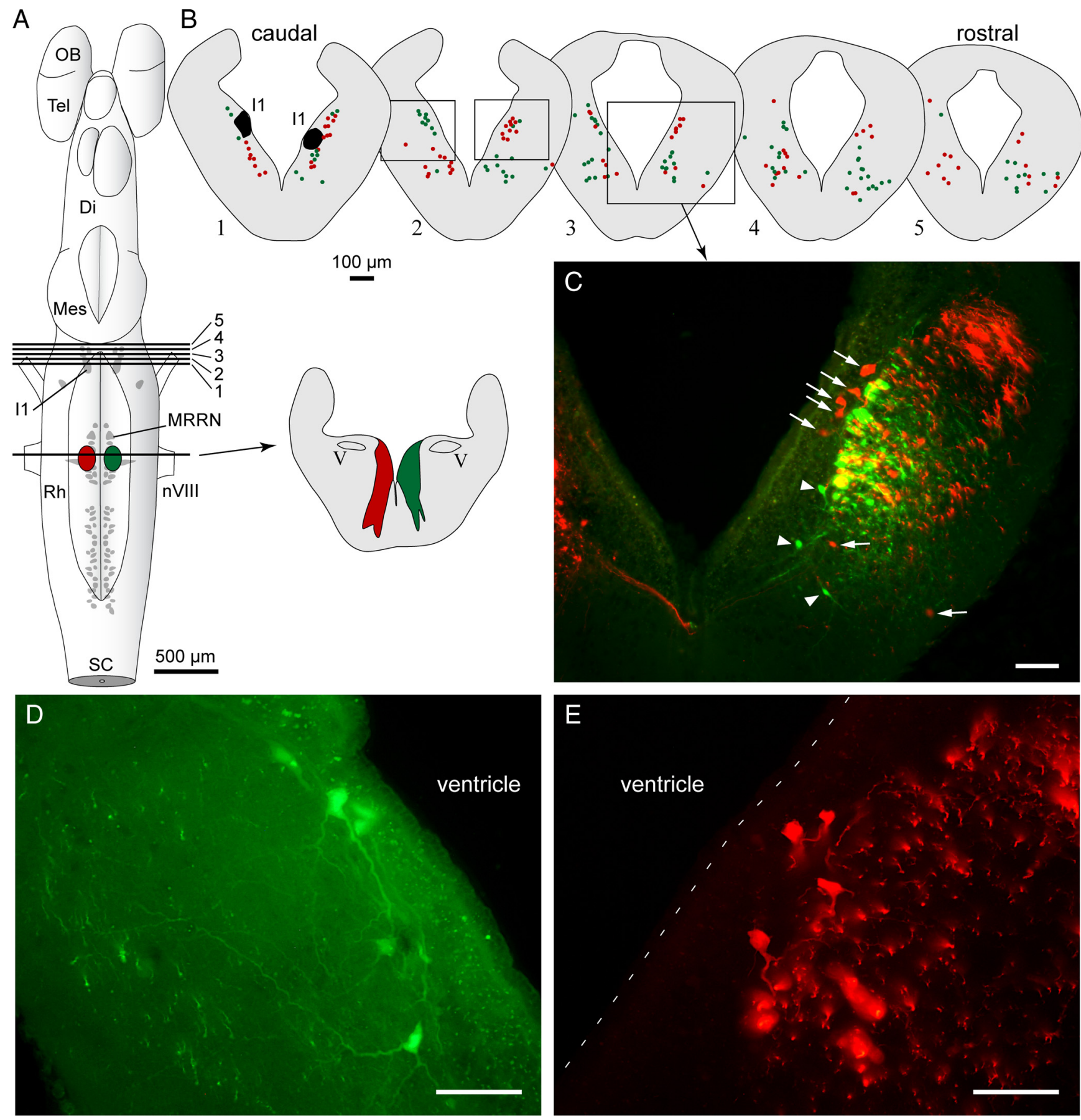

Figure 6. Distribution of retrogradely labeled cell bodies in the isthmic region after injection of two fluorescent dextran amine tracers in the MRRN, one on each side. $\boldsymbol{A}$, Schematized dorsal view of the brain of a larval stage lamprey showing approximate location of injection sites into the MRRN and the level of the cross sections $1-5$ represented in $\boldsymbol{B}$. The lesioned area from each injection is indicated on the cross section to the right. $\boldsymbol{B}$, Schematized cross sections of the brain at the isthmic levels indicated in $\boldsymbol{A}$ with colored dots, each representing one neuron labeled with its respective tracer. Double-labeled neurons were rarely found, and none were found in this particular animal. C, Photomicrograph illustrating an example of the distribution of labeled neurons in the isthmic region as seen in epifluorescence microscopy. The green neurons (arrowheads) are ipsilateral and the red neurons (arrows) are contralateral to their respective injection sites. All the other labeled structures are axons, some being larger than neurons, which is common in lampreys. The yellow color results from the superimposition of distinct green and red axons from different focal planes in the 25- $\mu \mathrm{m}$-thick section. $\boldsymbol{D}, \boldsymbol{E}$, Higher-power photomicrographs illustrating examples of neurons labeled with one of the two tracers. The approximate location of the picture frames is indicated on cross section 2 in $\boldsymbol{B}$. Di, Diencephalon; I1, Müller isthmic cell I1; Mes, mesencephalon; nVIII, vestibular nerve; OB, olfactory bulb; Rh, rhombencephalon; SC, spinal cord; Tel, telencephalon; V, trigeminal motor nucleus. The $100 \mu \mathrm{m}$ scale bar applies to all cross sections. Scale bars in photomicrographs $50 \mu \mathrm{m}$.

response threshold between the MLRs. It is possible that small differences in either the positioning of the electrode in the MLR on both sides and/or differences in the impedance of two stimulating electrodes might have been responsible for the asymmetrical responses.

\section{Origin of the symmetry of the MLR command}

We believe that electrical stimulation within the MLR recruits populations of neurons that project directly to the reticular formation in the hindbrain. It is unlikely that the stimulation would be recruiting only axons passing through the MLR. In support of 
A1
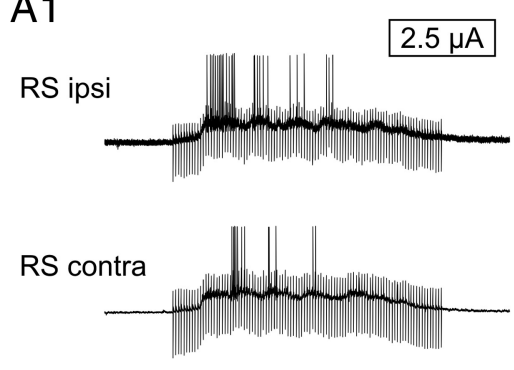

$3.5 \mu \mathrm{A}$
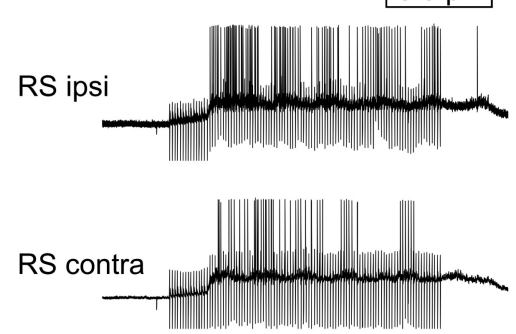

A2

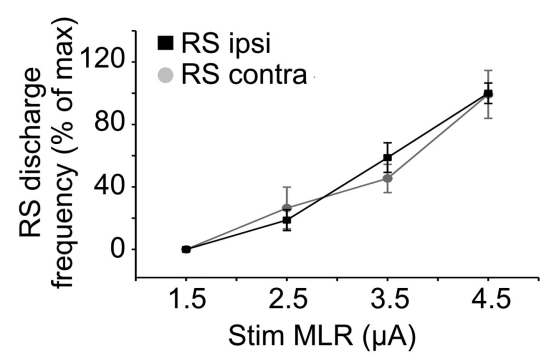

B1

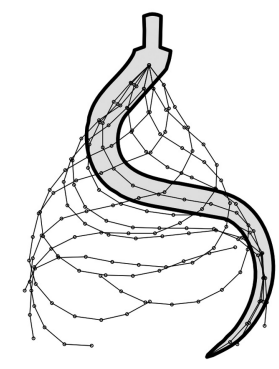

B3

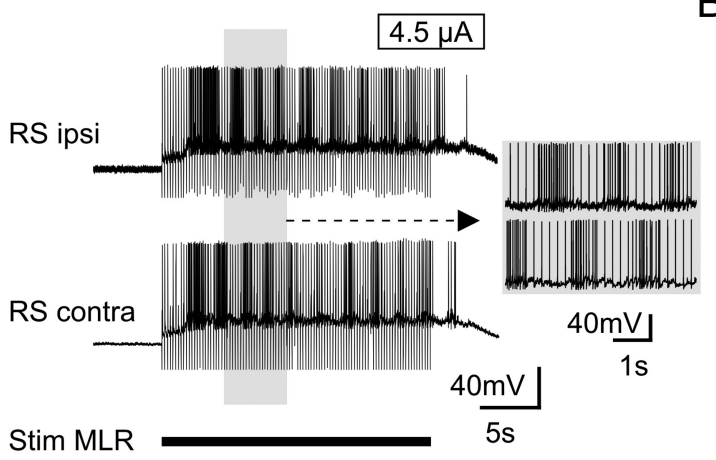

A3

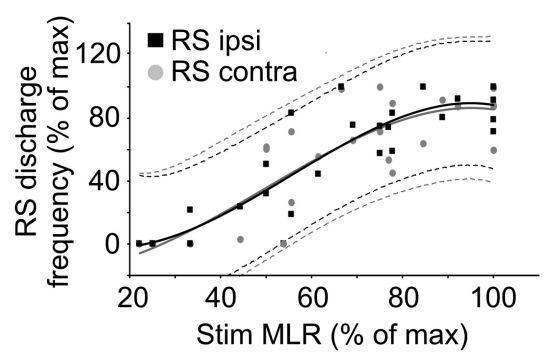

B2

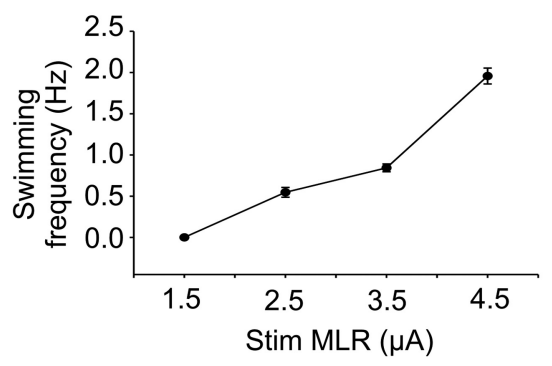

B4
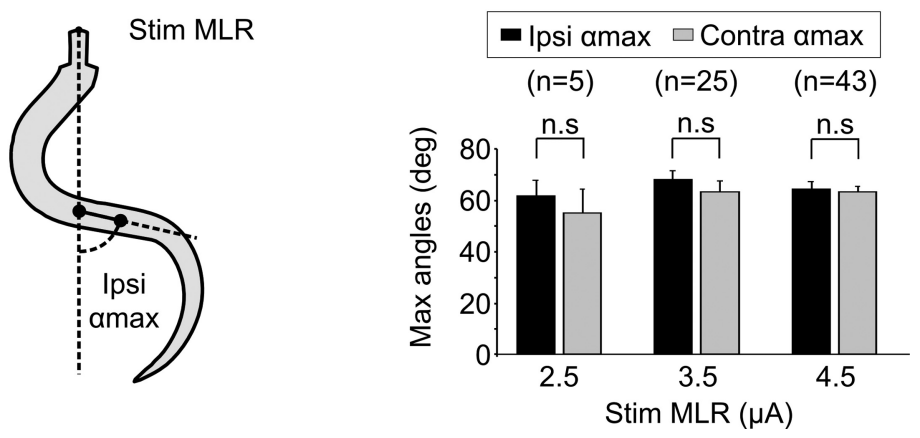

Figure 7. Bilateral recruitment of RS cells during MLR-induced swimming in a semi-intact preparation of larval lamprey. A1, Paired intracellular recordings from homologous ipsilateral (RS ipsi) and contralateral (RS contra) MRRN cells, during unilateral MLR electrical stimulation, at 2.5, 3.5, and 4.5 $\mu$ A. The duration of the electrical stimulation applied to the MLR is indicated by the stimulation bar (Stim MLR) below the recordings. Note the enlargement of the $4.5 \mu \mathrm{A}$ recording, illustrating the antiphasic relationship between ipsilateral and contralateral RS neurons. A2, Discharge frequencies of homologous ipsilateral and contralateral RS neurons in the same animal. Each dot illustrates the mean \pm SEM discharge frequency, for a 20 s bout of MLR stimulation. Each intensity was tested three times. RS discharge frequencies are expressed in percentage of the maximal RS discharge frequency. A3, Relationships between the intensity of unilateral stimulation of the MLR and the discharge frequencies of ipsilateral (black squares) and contralateral (gray dots) RS neurons in five animals. Both ipsilateral and contralateral data followed a cubic polynomial function (black and gray solid lines, respectively). The dotted lines illustrate the prediction intervals for each fit at $95 \%$. $\mathbf{B}$, Kinematic analysis (15 frames/s) of one representative swimming cycle during unilateral MLR stimulation (4.5 $\mu \mathrm{A}$ ). Tracking positions of markers equidistantly distributed along the body of the animal using software analysis allowed a kinematic analysis of the MLR-induced locomotion. $\mathbf{B 2}$, Relationship between the intensity of MLR stimulation and the frequency of swimming in the same animal. Swimming was evoked by applying the same stimulation parameters used in $\mathbf{A 2}$. Each dot illustrates the mean \pm SEM swimming frequency during one locomotor bout induced by the corresponding intensity of stimulation. $\boldsymbol{B}$, The maximal bending angles of the animal $\left(\alpha_{\text {max }}\right)$, ipsilateral and contralateral to the MLR stimulation site, were estimated in video images using the distributed markers (see Materials and Methods). Equal ipsilateral and contralateral bending angles were considered to describe a symmetrical swimming. B4, Mean maximal angles (absolute values) during MLR-induced swimming, ipsilateral (black bars) and contralateral (gray bars) to the stimulation site, in a semi-intact preparation, at three stimulation intensities. Each bar illustrates the mean \pm SEM maximal angle ipsilateral to the stimulation site (Ipsi $\alpha$ max) and contralateral to the stimulation site (Contra $\alpha \max$ ) during one locomotor bout induced by the corresponding intensity of stimulation. The number in parentheses indicates the number of locomotor cycles analyzed. n.S., Nonsignificant ( $p>0.05$, paired $t$ test). Data in $\boldsymbol{A} \mathbf{1}, \mathbf{A}, \mathbf{B} \mathbf{1}, \mathbf{B} \mathbf{2}$, and $\mathbf{B} \mathbf{4}$ are from the same animal.

this, we found that microinjections of AMPA into the MLR also recruited RS cells in a symmetrical bilateral manner. This would strongly suggest that the symmetry of the MLR command originates from cell bodies located in the vicinity of the stimulating electrode. The output neurons would then send their axon to either the ipsilateral or contralateral hindbrain reticular formation. This assumption is supported by the present anatomical findings. Injections in the hindbrain reticular formation on one side retrogradely labeled neurons in the MLR on both sides as described previously by us (Sirota et al., 2000). The double- labeling experiments in which one tracer was injected on one side and another one on the other side revealed intermingling populations of retrogradely labeled neurons in the MLR from the two sides with a larger number of cells on the side of the injection, suggesting some anatomical asymmetry that may be compensated physiologically. Indeed, our stimulation in the MLR was very local and as many ipsilaterally versus contralaterally projecting neurons could have been stimulated. Differential synaptic strength of individual MLR neurons may also compensate for the anatomical asymmetry. In other animal species, anterogradely 
labeled fibers from the MLR were distributed bilaterally in the reticular formation of cats and rats (Steeves and Jordan, 1984; Garcia-Rill et al., 1986). This again is in accord with the present results.

It is also very unlikely that direct electrical coupling between RS cells on the two sides would contribute to the symmetry of the MLR command in lampreys. We found no evidence of spike-triggered synaptic responses elicited in a contralateral RS cells by spike trains in one RS cell (data not shown). Anatomical experiments also argue against the possibility of a bilateral coupling between RS neurons in lampreys. The dendrites (Martin, 1979) and branching axons (Rovainen et al., 1973) of large RS cells do not cross the midline. However, we cannot exclude that some of the smaller RS cells on one side may project contralaterally to interact with RS cells on the other side.

\section{Functional significance}

The brainstem reticular formation comprises bilaterally symmetrical groups of RS cells. The contribution of RS cells to postural responses in maintaining balance in lampreys was investigated in detail by the group of Deliagina in Stockholm (for review, see Deliagina and Orlovsky, 2002; Deliagina et al., 2002, 2007, 2008). Postural perturbations were found to generate asymmetrical activation of RS cell. In the present paper, we show that initiation and maintenance of swimming by the MLR stimulation is associated with a powerful symmetry in the activation of RS cells on both sides. Regardless of the modality and laterality of the applied sensory stimulus to induce linear swimming, such symmetrical bilateral activation of the RS system has also been observed previously in swimming lampreys (Deliagina et al., 2002). One important functional implication of a symmetrical monosynaptic MLR input to RS cells would be to be a major contributor for the initiation of the well coordinated bilateral locomotion. This aspect associated with the differential recruitment of reticular nuclei and the regulation in firing rate of RS cells by the MLR (Brocard and Dubuc, 2003) could constitute fundamental neuronal mechanisms underlying the initiation of locomotion and the control of the speed of bilateral well coordinated locomotor movements. The importance of a bilaterally symmetrical input to RS cells is further stressed by the need for stimulating RS cells on both sides to elicit symmetrical locomotion. For instance, a unilateral chemical stimulation of reticular nuclei elicits asymmetrical undulations or uncoordinated movements in semi-intact preparations from larval lampreys, whereas bilateral stimulation elicited symmetrical swimming (Jackson et al., 2007). A bilateral symmetrical activation of RS cells is thus important for symmetrical locomotion but unlikely to be the sole contributor. Changes in direction would require a break in the symmetry. They were proposed to result from additional excitation of populations of RS cells on one side, allowing the body of the animal to change direction. This has been demonstrated experimentally (McClellan and Hagevik, 1997; Karayannidou et al., 2007).

The spinal locomotor networks are also likely to strengthen the symmetry of the locomotor output attributable to their bilateral connections. Other regions in the brain could also contribute. A diencephalic locomotor region was also shown to project monosynaptically to RS cells (El Manira et al., 1997) and to elicit locomotion in the same manner as the MLR (Ménard and Grillner, 2008). Injections of retrograde tracers into the MLR labeled a few neurons in the ventral thalamus in a region that could be the diencephalic locomotor region
(Ménard et al., 2007), and such projection could influence the balance of symmetry in RS cells. However, the existence of direct physiological interactions between the two regions remains to be shown (Ménard and Grillner, 2008). Experiments are underway to establish the relative contribution of ascending and descending inputs to the locomotor symmetry.

Collectively, our results show that symmetrical activation of the RS system on both sides by the MLR may be a significant contributor to the initiation and maintenance of bilaterally symmetrical locomotion.

\section{References}

Bar-Gad I, Kagan I, Shik ML (1999) Behavior of hindbrain neurons during the transition from rest to evoked locomotion in a newt. Prog Brain Res 123:285-294.

Brocard F, Dubuc R (2003) Differential contribution of reticulospinal cells to the control of locomotion induced by the mesencephalic locomotor region. J Neurophysiol 90:1714-1727.

Brocard F, Hatem R, Fénelon K, Dubuc R (2005) Symmetrical recruitment of reticulospinal cells on both sides by the mesencephalic locomotor region. Soc Neurosci Abstr 31:751.8.

Bussières N (1994) Les systèmes descendants chez la lamproie. Étude anatomique et fonctionnelle. $\mathrm{PhD}$ thesis. University of Montréal.

Deliagina TG, Orlovsky GN (2002) Comparative neurobiology of postural control. Curr Opin Neurobiol 12:652-657.

Deliagina TG, Zelenin PV, Orlovsky GN (2002) Encoding and decoding of reticulospinal commands. Brain Res Brain Res Rev 40:166-177.

Deliagina TG, Zelenin PV, Beloozerova IN, Orlovsky GN (2007) Nervous mechanisms controlling body posture. Physiol Behav 92:148-154.

Deliagina TG, Beloozerova IN, Zelenin PV, Orlovsky GN (2008) Spinal and supraspinal postural networks. Brain Res Rev 57:212-221.

Dubuc R (2009) Locomotor regions in the midbrain (MLR) and diencephalon (DLR). In: Encyclopedia of neuroscience (Binder MD, Hirokawa N, Windhorst U, eds), pp 2168-2171. Berlin, Heidelberg: Springer-Verlag.

Dubuc R, Brocard F, Antri M, Fénelon K, Gariépy JF, Smetana R, Ménard A, Le Ray D, Viana Di Prisco G, Pearlstein E, Sirota MG, Derjean D, St-Pierre M, Zielinski B, Auclair F, Veilleux D (2008) Initiation of locomotion in lampreys. Brain Res Rev 57:172-182.

El Manira A, Pombal MA, Grillner S (1997) Diencephalic projection to reticulospinal neurons involved in the initiation of locomotion in adult lampreys Lampetra fluviatilis. J Comp Neurol 389:603-616.

Garcia-Rill E, Skinner RD (1987) The mesencephalic locomotor region. II. Projections to reticulospinal neurons. Brain Res 411:13-20.

Garcia-Rill E, Skinner RD, Conrad C, Mosley D, Campbell C (1986) Projections of the mesencephalic locomotor region in the rat. Brain Res Bull $17: 33-40$.

Grillner S, Ekeberg, El Manira A, Lansner A, Parker D, Tegnér J, Wallén P (1998) Intrinsic function of a neuronal network: a vertebrate central pattern generator. Brain Res Brain Res Rev 26:184-197.

Iwakiri H, Oka T, Takakusaki K, Mori S (1995) Stimulus effects of the medial pontine reticular formation and the mesencephalic locomotor region upon medullary reticulospinal neurons in acute decerebrate cats. Neurosci Res 23:47-53.

Jackson AW, Pino FA, Wiebe ED, McClellan AD (2007) Movements and muscle activity initiated by brain locomotor areas in semi-intact preparations from larval lamprey. J Neurophysiol 97:3229-3241.

Jordan LM (1998) Initiation of locomotion in mammals. Ann N Y Acad Sci 860:83-93.

Kagan I, Shik ML (2004) How the mesencephalic locomotor region recruits hindbrain neurons. Prog Brain Res 143:221-230.

Karayannidou A, Zelenin PV, Orlovsky GN, Deliagina TG (2007) Responses of reticulospinal neurons in the lamprey to lateral turns. J Neurophysiol 97:512-521.

Le Ray D, Brocard F, Bourcier-Lucas C, Auclair F, Lafaille P, Dubuc R (2003) Nicotinic activation of reticulospinal cells involved in the control of swimming in lampreys. Eur J Neurosci 17:137-148.

Martin RJ (1979) A study of the morphology of the large reticulospinal neurons of the lamprey ammocoete by intracellular injection of Procion yellow. Brain Behav Evol 16:1-18.

McClellan AD, Hagevik A (1997) Descending control of turning locomotor 
activity in larval lamprey: neurophysiology and computer modeling. J Neurophysiol 78:214-228.

Ménard A, Grillner S (2008) Diencephalic locomotor region in the lamprey: afferents and efferent control. J Neurophysiol 100:1343-1353.

Ménard A, Auclair F, Bourcier-Lucas C, Grillner S, Dubuc R (2007) GABAergic projections to the mesencephalic locomotor region in the lamprey Petromyzon marinus. J Comp Neurol 501:260-273.

Orlovsky GN (1970) Work of the reticulo-spinal neurons during locomotion (in Russian). Biofizika 15:761-771.

Orlovsky GN, Deliagina TD, Grillner S (1999) Neuronal control of locomotion. New York: Oxford UP.

Rovainen CM (1967) Physiological and anatomical studies on large neurons of central nervous system of the sea lamprey (Petromyzon marinus). I. Müller and Mauthner cells. J Neurophysiol 30:1000-1023.
Rovainen CM (1978) Müller cells, "Mauthner" cells, and other identified reticulospinal neurons in the lamprey. In: Neurobiology of the Mauthner cell (Faber DS, Korn H, eds), pp 245-269. New York: Raven.

Rovainen CM, Johnson PA, Roach EA, Mankovsky JA (1973) Projections of individual axons in lamprey spinal cord determined by tracings through serial sections. J Comp Neurol 149:193-202.

Shik ML, Severin FV, Orlovsky GN (1966) Control of walking and running by means of electrical stimulation of the midbrain (in Russian). Biofizika 11:756-765.

Sirota MG, Di Prisco GV, DubucR (2000) Stimulation of the mesencephalic locomotor region elicits controlled swimming in semi-intact lampreys. Eur J Neurosci 12:4081-4092.

Steeves JD, Jordan LM (1984) Autoradiographic demonstration of the projections from the mesencephalic locomotor region. Brain Res 307:263-276. 